\title{
Pelaksanaan Penyimpanan Rekam Medis Berdasarkan Unsur Manjemen 5M di Puskesmas Medan Johor
}

\author{
Valentina $^{1}$, Winda Andryani Sinaga ${ }^{2}$ \\ ${ }^{1,2}$ Program Studi D-III Perekam dan Informasi Kesehatan, Universitas Imelda Medan
}

\begin{tabular}{l}
\hline \hline Article Info \\
\hline Article history: \\
Received Jul 07, 2021 \\
Revised Jul 19, 2021 \\
Accepted Jul 26, 2021 \\
\end{tabular}

Keywords:

Storage

Medical Records

$5 \mathrm{M}$

Management

Puskesmas

\begin{abstract}
Storage of medical records needs to be managed properly in order to create an orderly administration in supporting health services at the puskesmas. The purpose of this study was to determine the implementation of medical record storage based on management elements (man, money, material, machine, and method) at the Puskesmas Medan Johor. The research uses qualitative research methods with a phenomenological approach. The population is all medical record officers at the Puskesmas Medan Johor. The research sample amounted to 5 people who were taken by saturated sampling. The instrument used was an interview guide which was recorded with an audio recorder and an observation sheet. The results of the study found that the man element showed that the competence of the officers did not match the PMIK qualifications. The money element shows that the need for medical record storage has been fulfilled in the operational budget. The material element, namely the use of a family folder folder and a filling cabinet used as a tool to store medical record files is good. The machine element does not use a computerized system, there is no use of tracers and register books in the process of borrowing medical records. The method elements are not entirely in the form of SOPs and work procedures. It is recommended to the Puskesmas Medan Johor to recruit medical record officers who have a medical record educational background or provide medical record training, make tracers and expedition books.
\end{abstract}

\section{Corresponding Author:}

This is an open access article under the $\underline{C C B Y-S A l i c e n s e .}$

Valentina,

Program Studi D-III Perekam dan Informasi Kesehatan,

Universitas Imelda Medan,

Jl. Bilal No. 52 Kelurahan Pulo Brayan Darat I Kecamatan Medan Timur, Medan - Sumatera Utara.

Email: valentinave89@gmail.com

\section{PENDAhUluan}

Pusat Kesehatan Masyarakat (Puskesmas) adalah fasilitas pelayanan kesehatan yang menyelenggarakan upaya kesehatan masyarakat dan masyarakat perseorangan tingkat pertama melalui promosi dan pencegahan yang diprioritaskan untuk mencapai derajat kesehatan masyarakat yang setinggi-tingginya di wilayah tempat bekerjanya [1]. Dalam penyelenggaraan upaya kesehatan tersebut, puskesmas wajib membuat pengadaan rekam medis untuk membantu kelancaran proses pelayanan kesehatan kepada pasien [2] dan mendukung tercapainya tertib administrasi di puskesmas [3]. Sistem pengelolaan rekam 
medis pada tingkat puskesmas pada dasarnya sama dengan rekam medis rumah sakit [4]. Pelayanan kesehatan di puskesmas memerlukan manajemen dalam mengelola rekam medis agar terciptanya pelaksananaan rekam medis yang baik. Manajemen merupakan proses kegiatan yang terdiri dari pengaturan, perencanaan, pengorganisasian, pengarahan dengan melalui penggunaan sumber daya manusia dan sumber daya lainnya secara efektif dan efisien mencapai tujuan organisasi, sehingga menentukan dan mencapai tujuan. Untuk mencapai tujuan tersebut diperlukan lima unsur manajemen atau fasilitas manajemen, yaitu orang, uang, benda, mesin dan metode [5].

Penyimpanan rekam medis merupakan salah satu bagian yang sering bermasalah. Penelitian di Puskesmas Kotanopan Mandailing Natal menjelaskan pengembalian dan penyimpanan yang tidak sesuai prosedur sehingga banyak terjadi misfile, terjadinya penumpukan dokumen yang menyebabkan terhambatnya pelayanan pasien di bagian pendaftaran [6]. Penelitian lainnya di Puskesmas Ngalik 1 Sleman diketahui bahwa pengambilan dan pengembalian rekam medis belum menggunakan tracer sebagai alat ganti rekam medis yang dipinjam untuk keperluan apapun sehingga menghambat dalam penyediaan rekam medis pasien yang diperlukan [7]. Penyimpanan berkas rekam medis yang tidak sesuai dengan prosedur dan pedoman dapat mengakibatkan hilangnya suatu informasi terhadap catatan rekam medis. Masalah seperti ini dapat terjadi terhadap suatu fasilitas layanan kesehatan yang tidak menjalankan sistem penyimpanan rekam medis dengan baik [8].

Puskesmas Medan Johor merupakan salah satu Unit Pelaksana Teknis (UPT) Dinas Kesehatan Kota Medan. Berdasarkan observasi awal dilakukan di Puskesmas Medan Johor. Menurut salah seorang petugas di puskesmas tersebut, dokumen rekam medis pasien masih ada yang tidak ditemukan di dalam rak penyimpanan. Dokumen rekam medis memiliki jumlah ganda serta terduplikasi dalam penomoran rekam medis masih sering terjadi. Dalam pengendalian dokumen rekam medis, untuk setiap berkas yang keluar dari rak penyimpanan belum memiliki tracer (outguide). Tidak adanya tracer mengakibatkan rekam medis yang keluar menjadi tidak diketahui keberadaaanya. Di puskesmas tersebut, dokumen rekam medis juga jarang di retensi. Petugas akan melakukan retensi setiap 5 tahun sekali bersamaan dengan pemusnahannya. Hal ini mengakibatkan penuhnya volume rekam medis di rak penyimpanan dan membutuhkan tempat yang lebih besar untuk menyimpan berkas pasien yang baru. Dalam pelaksanaannya, masih terdapat kendala seperti petugas rekam medis yang bertanggung jawab atas pelaksanaan rekam medis belum ada yang memiliki latar belakang pendidikan rekam medis.

Masalah seperti ini dapat terjadi terhadap suatu fasilitas layanan kesehatan yang tidak menjalankan sistem penyimpanan rekam medis dengan baik, kurangnya perhatian khusus terhadap rekam medis, SDM yang kurang dan unit rekam medis yang justru menjalankan berbagai pekerjaan sehingga tidak fokus menangani pengelolaan rekam medis. Hal ini membuat peneliti tertarik ingin melihat pelaksanaan penyimpanan rekam medis berdasarkan unsur manajemen 5M (Man, Money, Material, Machine, Methode) di Puskesmas Medan Johor.

\section{METODE PENELITIAN}

A. Jenis Penelitian

Penelitian yang dilakukan adalah penelitian deskriptif kualitatif dengan tujuan untuk mendapatkan informasi yang jelas tentang unsur manajemen 5M (Man, Money, Material, Machine, Methode) dalam kegiatan pelaksanaan rekam medis di Puskesmas Medan Johor.

B. Populasi

Populasi yang digunakan adalah seluruh petugas rekam medis di Puskesmas Medan Johor sebanyak 5 orang. 
C. Sampel

Sampel penelitian ini yaitu petugas rekam medis di Puskesmas Medan Johor sebanyak 5 orang yang diambil secara sampling jenuh.

D. Instrumen Penelitian

Instrumen yang digunakan adalah wawancara yang direkam dengan alat perekam audio dan lembar check list.

E. Cara Pengumpulan Data

Pengumpulan data dalam penelitian ini dilakukan dengan metode wawancara dan observasi. Wawancara dilakukan kepada petugas rekam medis untuk mendapatkan data unsur 5M. Sedangkan observasi untuk mengamati unsur material, machine dan methode.

F. Analisis Data

Analisis data dilakukan secara deskriptif yaitu memperoleh gambaran yang jelas tentang pelaksanaan penyimpanan rekam medis berdasarkan unsur manajemen $5 \mathrm{M}$ di Puskesmas Medan Johor.

\section{HASIL DAN PEMBAHASAN}

\subsection{Hasil}

Berdasarkan hasil wawancara diperoleh informasi bahwa sumber daya manusia yang mengelola rekam medis di Puskesmas Medan Johor berjumlah 5 orang dengan latar belakang seluruhnya bukan perekam medis, seperti yang tertuang pada tabel 1 .

Tabel 1. Karakteristik Informan

\begin{tabular}{ccc}
\hline Petugas Rekam Medis & Jenis Kelamin & Pendidikan \\
\hline Informan 1 & Perempuan & D-III Keperawatan \\
\hline Informan 2 & Perempuan & D-III Keperawatan \\
\hline Informan 3 & Perempuan & D-III Kebidanan \\
\hline Informan 4 & Perempuan & D-III Kesehatan Lingkungan \\
\hline Informan 5 & Perempuan & D-III Gizi \\
\hline
\end{tabular}

Berdasarkan hasil wawancara mengenai unsur man tentang keikutsertaan pelatihan rekam medis, seluruh informan belum pernah mengikuti pelatihan rekam medis. Kegiatan penyimpanan rekam medis dilakukan sesuai apa yang mereka ketahui saja. Sesuai dengan pernyataan informan:

"Sejauh ini sih belum pernah ikut pelatihan. Kami disini hanya dibagi tugas saja siapa di penyimpanan dan di tempat lain, gak pernah ada diberikan pelatihan tentang rekam medis, ya tau setelah bekerja saja." (Informan 1).

Hasil wawancara tentang unsur money di bagian rekam medis adalah sebagai berikut: "Untuk semua pembelanjaan sudah rutin dilakukan selama $2 x$ setahun, sudah di stock berapa lembar yang dibutuhkan untuk family folder atau berapa ribu lembar untuk status, rak dan yang lainnya. Nanti itu semua diperoleh dari JKN dan APBD, dan sebelumnya sudah dianggarkan terlebih dahulu sesuai kebutuhan di rekam medisnya." (Informan 2). 
Berdasarkan hasil observasi mengenai unsur material diperoleh data sebagai berikut:

Tabel 2. Unsur Material dalam Penyimpanan Rekam Medis

\begin{tabular}{cll}
\hline No & \multicolumn{1}{c}{ Pengamatan } & \multicolumn{1}{c}{ Keterangan } \\
\hline 1 & Map Family Folder & $\begin{array}{l}\text { Terdapat map sebagai tempat untuk menyimpan } \\
\text { formulir rekam medis serta identitas pasien dalam satu } \\
\text { keluarga }\end{array}$ \\
\hline 2 & $\begin{array}{l}\text { Formulir Rekam } \\
\text { Medis }\end{array}$ & $\begin{array}{l}\text { Formulir yang berisi data diri setiap pasien dalam satu } \\
\text { keluarga }\end{array}$ \\
\hline 3 & Filling Cabinet & $\begin{array}{l}\text { Laci yang digunakan untuk menyimpan berkas rekam } \\
\text { medis }\end{array}$ \\
\hline 4 & Tracer & $\begin{array}{l}\text { Petugas tidak menggunakan tracer sebagai alat untuk } \\
\text { mengendalikan berkas yang keluar atau dipinjam }\end{array}$ \\
\hline 5 & Buku Ekspedisi & $\begin{array}{l}\text { Tidak ada penggunaan buku eskpedisi untuk menulis } \\
\text { peminjaman dan pemulangan berkas rekam medis. }\end{array}$ \\
\hline
\end{tabular}

Hasil wawancara tentang ditemukannya map yang sudah rusak, maka jawaban informan adalah sebagai berikut:

"Kalau ada map family folder yang sudah rusak langsung kami ganti yang baru. Isi mapnya itu pun status pasien, fotocopy status pasien per orang sesuai nama yang tertera di kartu keluarga, fotocopy kartu keluarga, fotocopy kartu BPJS." (Informan $3)$.

Mengenai unsur material lainnya yaitu rak penyimpanan, maka jawaban informan adalah sebagai berikut:

"Kami tidak pakai rak tapi kami fungsikan filling cabinet untuk menyimpan family folder, bentuknya laci. Kami menggunakan 6 filling cabinet, dan per filling cabinet ada 4 laci. Lalu lacinya kami nomori, 1 laci berisi kurang lebih 200 family folder." (Informan 3).

Berdasarkan hasil wawancara tentang proses peminjaman rekam medis, maka jawaban informan adalah sebagai berikut:

"Berkas kami yang keluar tidak pernah dipinjam. Berkasnya keluar karena dipakai selama pelayanan, tapi setiap keluar tidak pernah ditulis ke dalam buku ekspedisi dan tidak pernah memakai tracer juga. Setelah selesai pelayanan itu, barulah petugas poli yang mengantarkan ke rekam medis, nanti petugas rekam medisnya yang susun ke laci langsung hari itu juga. Kami juga tidak tahu apa tracer”. (Informan 3).

Berdasarkan hasil wawancara tentang unsur mechine, maka jawaban informan adalah sebagai berikut:

"Pengantaran berkas ke ruangan sampai penyimpanannya kami masih manual." (Informan 4).

Berdasarkan hasil wawancara yang diperoleh dari informan tentang unsur methode yaitu SOP, maka jawaban informan adalah sebagai berikut:

"SOP penyimpanan ada, tapi kalau yang lain misalnya peminjaman dan pendistribusian begitu belum ada, dan tetap berjalan seperti biasa saja” (Informan 5).

Mengenai sistem penyimpanan maka jawaban informan sebagai berikut:

"Kami pakai sistem penyimpanan family folder, satu map untuk satu keluarga. Kalau penjajarannya yang seperti mengurutkan nomor biasa aja contohnya 001, 002 begitu, dan penomorannya mengikuti nomor kepala keluarganya, pokoknya satu nomor 
semua yang ada di dalam map itu, nanti nomor itulah yang dipakai untuk pelayanan seterusnya." (Informan 5).

Hasil wawancara mengenai sistem penomoran rekam medis, maka jawaban informan sebagai berikut:

"Penomoran yang kami pakai ini meneruskan dari kepala keluarganya saja, mereka satu nomor untuk satu keluarga. Misalnya kepala keluarganya nomor 001, nanti istrinya dapatlah 001a, si anak 001b begitulah seterusnya. Untuk penyimpanan berkasnya pun dibedakan lacinya. Duplikasi nomor masih sering juga, karna sering kali petugasnya ini lupa nulis lagi ke buku register. Misalnya hari ini udah ditulis nomor 1200, tapi karena lupa ditulis lagi ke buku register, jadi besok dikasi lagi ke orang lain nomor 1200, begitulah." (Informan 5).

Selanjutnya mengenai adanya kejadian missfile atau salah letak maka jawaban informan sebagai berikut:

"Berkas yang hilang kadang-kadang terjadi ya. Dia pernah berobat, tapi berkasnya tidak ketemu. Sudah kami cari tapi tidak ketemu. Nah ini juga yang kadang membuat antrian pasien jadi lama." (Informan 2).

"Kalau salah menyimpan berkas masih ada, karna petugasnya kadang buru-buru waktu mau menyimpan status pasien itu makanya tidak diliat lagi ada nomor yang mirip, akhirnya salah letak. Kami mengecek berkas hanya ketika si pasien datang berobat saja, disitulah diperiksa mana yg belum lengkap, seperti tanggal dan yang lainnya." (Informan 5).

\subsection{Pembahasan}

\section{a. Unsur Man (SDM) dalam Pelaksanaan Penyimpanan Rekam Medis}

Hasil penelitian yang diperoleh bahwa SDM di bagian rekam medis Puskesmas Medan Johor, belum ada yang memiliki latar belakang pendidikan rekam medis. Berdasarkan pengamatan yang dilakukan di bagian rekam medis, penyimpanan rekam medis belum dilaksanakan dengan tepat karena dikerjakan berdasarkan hanya pada apa yang mereka ketahui saja.

Profesi Perekam Medis adalah seseorang yang telah lulus pendidikan rekam medis dan informasi kesehatan sesuai dengan ketentuan peraturan perundang-undangan [9]. Profesi perekam medis harus menguasai kompetensinya sebagai seorang perekam medis. Salah satu dari lima kompetensi pokok yaitu manajemen rekam medis dan informasi kesehatan, menjaga dan meningkatkan mutu rekam medis \& informasi kesehatan. Kompetensi ini sangat dibutuhkan untuk meningkatkan mutu manajeman rekam medis sehingga tercipta tertib administrasi dalam mendukung pelayanan kesehatan [10].

Berdasarkan hasil penelitian, petugas rekam medis yang bertanggung jawab di bagian rekam medis juga belum pernah mendapat pelatihan tentang rekam medis. Hal ini tidak sesuai dengan isi Permenkes RI No 55 tahun 2013 bahwa pelayanan rekam medis harus dilakukan oleh seorang perekam medis yang memiliki kompetensi berdasarkan pendidikan dan pelatihan, serta wajib memenuhi standar industri perekam medis [11]. Petugas rekam medis yang tidak memiliki kompetensi dan keterampilan yang baik menyebabkan pelaksanaan penyimpanan rekam medis menjadi terkendala misalnya terjadinya misfile, duplikasi, dan waktu tunggu pasien yang panjang. Untuk itu diperlukan sumber daya manusia yang memenuhi kemampuan perekam medis untuk bekerja di unit rekam medis khususnya pada bagian penyimpanan rekam medis. 


\section{b. Unsur Money dalam Pelaksanaan Penyimpanan Rekam Medis}

Dana merupakan salah satu yang paling berperan untuk mencapai suatu sistem di instansi pelayanan kesehatan agar tercapai pelayanan yang baik dan cepat sesuai dengan yang diharapkan pasien [12]. Di Puskesmas Medan Johor, dana pada bagian rekam medis tidak diperoleh dalam bentuk uang melainkan barang. Petugas rekam medis sudah menyusun dalam rincian keperluan yang dibutuhkan dalam pelaksanaan penyimpanan rekam medis kemudian ada tenaga medis lain yang bertanggung jawab membuat anggaran yang berisikan segala kebutuhan dalam rekam medis, dan dana tersebut akan diperoleh dari JKN (Jaminan Kesehatan Nasional) dan APBD (Anggaran Pendapatan dan Belanja Daerah).

Setelah dana sudah ada, maka barang yang diperlukan akan diberikan ke bagian rekam medis. Anggaran dana dibutuhkan dalam pelaksanaan penyimpanan rekam medis untuk meningkatkan kualitas pelayanan pada pasien. Dana atau biaya sebagai sarana manajemen harus digunakan sedemikian rupa agar target yang telah di sepakati dapat tercapai [13].

\section{c. Unsur Material dalam Pelaksanaan Penyimpanan Rekam Medis}

Berdasarkan hasil penelitian yang diperoleh, formulir rekam medis pasien sudah disimpan di dalam satu map yang disebut family folder. Seluruh identitas pasien dalam satu keluarga sudah disatukan di dalam satu map. Isi dari map family folder antara lain formulir data diri pasien sesuai nama yang tertera di dalam kartu keluarga, fotocopy kartu keluarga, fotocopy kartu BPJS. Hal ini sesuai dengan penelitian dimana rekam medis berisi data dan informasi pelayanan pasien yang bersifat rahasia, sehingga setiap formulir rekam medis harus dilindungi dengan cara memasukkannya ke dalam map atau map berbentuk folder [14].

Map family folder tersebut terbuat dari karton yang tipis sehingga masih banyak ditemukan map yang robek dan rusak dan banyak coretan. Hal ini tidak sesuai [15], karena map (folder) merupakan pelindung kertas yang terbuat dari bahan karton yang lebih tebal, manila atau plastik. Map yang digunakan belum menggunakan bahan karton yang lebih tebal sehingga menyebabkan map mudah rusak.

Alat penyimpanan yang digunakan untuk menyimpan seluruh rekam medis pasien di Puskesmas Medan Johor yaitu filling cabinet. Berdasarkan pengamatan yang dilakukan, filling cabinet yang digunakan sudah menggunakan kunci agar berkas rekam medis tetap tersimpan aman. Salah satu alat penyimpanan rekam medis yaitu rak penyimpanan. Ada 3 jenis rak yang biasanya digunakan, antara lain rak terbuka, roll o'pack dan lemari 5 laci (filling cabinet) [14]. Unsur material ataupun sarana prasarana sangat penting dalam mendukung penyimpanan rekam medis. Sarana prasarana penyimpanan yang baik mencegah terjadinya kerusakan, kehilangan (misfile), duplikasi serta menjamin aspek kerahasiaan rekam medis. Unsur material penyimpanan rekam medis di Puskesmas Johor perlu ditingkatkan khususnya pengadaan tracer, buku ekspedisi, serta material map family folder.

\section{d. Unsur Machine dalam Pelaksanaan Penyimpanan Rekam Medis}

Berdasakan hasil wawancara yang diperoleh informasi bahwa pelaksanaan yang dilakukan masih secara manual. Data rekam medis tersimpan dalam bentuk paper based sehingga tidak ada bantuan komputerisasi dalam pelaksanaan penyimpanannya. Hasil observasi yang dilakukan di Puskesmas Medan Johor, penggunaan tracer dan buku ekspedisi belum diterapkan. Hal ini dapat menyebabkan berkas rekam medis pasien tidak diketahui keberadaannya atau bisa menyebabkan kesalahan letak (missfile). Menurut IFHIMA [16], tracer (outguide) yaitu pengganti rekam medis yang dikeluarkan dari penyimpanan untuk tujuan apapun. Tracer harus dari bahan yang kuat dan berwarna sehingga dapat menunjukkan letak rekam medis yang dipinjam ataupun dikeluarkan dari 
tempat penyimpanan. Tracer juga meningkatkan akurasi dan efisiensi waktu dengan menunjukkan letak rekam medis disimpan saat kembali [12]. Hal ini belum sesuai dengan hasil penelitian di Puskesmas Medan Johor karena belum ada penggunaan tracer beserta buku ekspedisi untuk menulis tanggal dan tujuan poli yang meminjam rekam medis.

Langkah-langkah pengambilan berkas rekam medis adalah menerima tracer yang telah diisi, mencari nomor rekam medis, memasukkan tracer pada posisi pengambilan rekam medis, mencari rekam medis yang ditemukan, dan mencatat rekam medis dan buku ekspedisi [17].

\section{e. Unsur Methode dalam Pelaksanaan Penyimpanan Rekam Medis}

Berdasarkan hasil penelitian yang diperoleh, pelaksanaan dilaksanakan sesuai SOP (Standar Operasional Prosedur). Namun SOP tersebut belum mencakup peminjaman dan pendistribusian rekam medis. Beberapa kegiatan yang tidak menggunakan SOP dapat menyebabkan pekerjaan menjadi dilakukan secara otodidak dan dapat menyebabkan pekerjaan menjadi tidak rapi dan tidak tertib karena tidak ada panduan dalam melakukan kegiatan tersebut. SOP (Standar Operasional Prosedur) adalah sistem yang dilakukan secara baik dengan berurutan mulai awal sampai terakhir yang disusun untuk merapikan, menertibkan dan memudahkan dan pekerjaan kita [18].

Sistem penyimpanan yang diterapkan di Puskesmas Medan Johor adalah family folder dimana satu map/folder rekam medis digunakan untuk satu keluarga dan masing-masing formulir diberi tambahan kode khusus untuk membedakan rekam medis milik ayah, ibu, dan anak. Sistem penomoran menggunakan family numbering dimana penomoran ini dipakai untuk satu keluarga (satu nomor untuk satu keluarga) [16]. Sistem penjajaran yang diterapkan yaitu sistem penjajaran numerik biasa dimana penjajaran ini dimulai dari nomor yang terkecil sampai yang terbesar misalnya nomor 001, 002 dan seterusnya.

Penjajaran rekam medis terdiri dari 6 digit angka yang terbagi menjadi 3 kelompok, dan setiap kelompok terdiri dari 2 angka. Dengan demikian, terdapat kelompok angka awal, tengah dan akhir [14]. Hal ini belum sesuai dengan penjajaran yang ada di Puskesmas Medan Johor yang menggunakan penjajaran numerik biasa dan belum memiliki 6 digit dalam penomorannya. [16] sistem penomoran family numbering adalah sistem penomoran yang biasa digunakan di puskesmas dimana semua anggota keluarga dapat menerima perawatan kesehatan. Hal ini sudah sesuai karena sudah ada penerapan sistem penomoran family numbering di Puskesmas Medan Johor, akan tetapi dalam pelaksanaannya terdapat kelemahan yaitu dengan diterapkannya satu nomor untuk satu keluarga dapat menyebabkan tertukarnya formulir antar anggota keluarga. Oleh karena itu, dibutuhkan kode nomor tambahan untuk membedakan tiap anggota keluarga yang ada di dalam satu map family folder.

\section{KESIMPULAN}

Unsur man menunjukan kompetensi petugas belum sesuai kualifikasi PMIK. Unsur money menunjukan kebutuhan di bagian penyimpan rekam medis sudah tercukupi dalam anggaran operasional. Unsur material yaitu penggunaan map family folder dan filling cabinet digunakan sebagai alat untuk menyimpan berkas rekam medis sudah baik. Unsur machine tidak menggunakan sistem komputerisasi, tidak adanya penggunaan tracer dan buku register dalam proses peminjaman rekam medis. Unsur methode belum seluruhnya berbentuk SOP dan prosedur kerja. Disarankan kepada Puskesmas Medan Johor agar merekrut petugas rekam medis yang memiliki latar belakang pendidikan rekam medis atau memberikan pelatihan rekam medis, membuat tracer dan buku ekspedisi. 


\section{REFERENCES}

[1] Permenkes RI. 2014, Peraturan Menteri Kesehatan Republik Indonesia Nomor 75 Tahun 2014 tentang Pusat Kesehatan Masyarakat (Puskesmas). Jakarta, 2014.

[2] Sanjoyo, Aspek Hukum Rekam Medis. Yogyakarta: UGM Press, 2013.

[3] M. Dewi, "Manajemen pada Kegiatan Pengelolaan Sistem Rekam Medis Pasien di Puskesmas Kedungmundu Semarang," Semarang, 2016.

[4] M. Sarake, Buku Ajar Rekam Medis. Jakarta, 2014.

[5] Henny Ulfa, "Analisis Unsur Manajemen Dalam Pengelolaan Rekam Medis di Rumah Sakit TNI AU-Lanud Roesmin Nurjadin," J. IKesmas, vol. 1, no. 1, pp. 1-6, 2018.

[6] Z. R. Andi and Hasran Ependi Lubis, "Tinjauan Pelaksanaan Sistem Penyimpanan Rekam Medis Berdasarkan Standar Akreditasi Di UPTD Puskesmas Kotanopan Mandailing Natal," J. Ilm. Perekam Dan Inf. Kesehat. Imelda, vol. 6, no. 1, pp. 1422., 2021.

[7] H. Fattimah and Rawi Miharti, "Tinjauan Pelaksanaan Sistem Penyimpanan Berkas Rekam Medis Paska Akreditasi Di Puskesmas Ngaglik 1 Kabupaten Sleman Tahun 2017," Yogyakarta, 2017.

[8] H. M. Ulfa, "Analisis pelaksanaan Pengelolaan Rekam Medis di Puskesmas Harapan Raya Kota Pekan Baru," Manaj. Inf. Kesehat. Indones., vol. 3, no. 2, pp. 39-40, 2015.

[9] Permenkes RI. 2013, Peraturan Menteri Kesehatan Nomor 55 Tahun 2013 tentang Penyelenggaraan Pekerjaan Perekam Medis. Indonesia, 2013.

[10] Kementrian Kesehatan RI, Keputusan Menteri Kesehatan Republik Indonesia Nomor:377/MENKES/SK/III/2007 Tentang Standar Profesi Perekam Medis dan Informasi Kesehatan. Jakarta, 2007.

[11] Permenkes RI. 2013, Peraturan Menteri Kesehatan Republik Indonesia Nomor 55 Tahun 2013 Tentang Penyelenggaraan Pekerjaan Perekam Medis. Indonesia, 2013.

[12] S. C. Budi, "Tracer Sebagai Kartu Pelacak Berkas Rekam Medis Keluar Dari Rak Penyimpanan. Jurnal Pengabdian kepada Masyarakat," (Indonesian J. Community Engag., vol. 1, no. 1, pp. 121-132, 2015.

[13] A. M and Budi W, Pengantar Manajemen, 1st ed. Yogyakarta: Deepublish, 2018.

[14] S. C. Budi, Manajemen Unit Kerja Rekam Medis. Yogyakarta: Quantum Sinergis Media., 2011.

[15] WHO, Medical Record Manual: A Guide A for Developing Countries Geneva. WHO, 2006.

[16] IFHIMA, "Education Module for Health Record Practice Module 3 - Record Identification Systems, Filing and Retention of Health Records". 2012.

[17] R. E and Rahayu W Amba, Manajemen Filing Dokumen Rekam Medis dan Informasi Kesehatan. Yogyakarta: Poltekkes Permata Indonesia.

[18] S. Ekotama, Pedoman Mudah Menyusun SOP. Yogyakarta: Media Press indo, 2015. 


\section{BIOGRAPHIES OF AUTHORS}

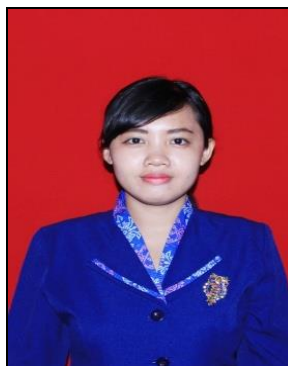

Valentina, Gelar Sarjana dari FKM Universitas Sumatera Utara pada tahun 2011. Magister Kesehatan Masyarakat diperoleh dari FKM USU pada tahun 2015. Saat ini aktif sebagai pengajar di Program Studi D-III Perekam dan Informasi Kesehatan Universitas Imelda Medan. 